\title{
Estimation of user benefit for river water quality: Indian case study
}

\author{
S. B. Imandoust \\ Payam noor University, Iran
}

\begin{abstract}
One of the most important problems in Indian cities is river pollution. Pune city is an industrial city in India that has three rivers. One of these is called Pavana that is located in an industrial area. In this study, researchers tried to find the user benefit, and the Contingent Valuation method was utilized for valuation of the river water quality in the Pavana River. Five categories of users have been chosen and then interviewed: householders, farmers, fishermen, washing clothes women, and people who bathe in the river. All these five directly use Pavana River, thus river water quality is very important for them. Researchers covered a distance of up to one kilometre each side of the river for sampling with 305 people interviewed. The average amount of those willing to pay was estimated at 17.6 Rs per family per month by researchers. With the use of the latest data, total user benefit has been estimated for all the people who live near the Pavana River. Finally, recommendations are presented for improving river quality in Pavana. This research shows Contingent Valuation is applicable in developing countries and river water quality is very important for people in Pune city.
\end{abstract}

Keywords: contingent valuation, willingness to pay, water pollution.

\section{Introduction}

Three rivers flow through Pune Metropolitan region, Mula, Mutha and Pavana. These rivers provide many services to the society. We need rivers because they are the source for drinking water, irrigation, fishing and so on. But it is felt that the quality of water in the Pune rivers should be improved. Unfortunately, all three rivers are highly polluted with untreated domestic sewage and industrial effluents. 
Nowadays, one of the important factors in environmental economics is the pollution problem in industrial cities. Presently, Pune is the seventh ranking industrial metropolis in India. There were 1,473 industrial units in 1972 in Pune which reached 4,527 by 1984 and 5,838 in 1995, Nagarkar [1], and more than 6195 in the industrial area are shown in the Indian Census [2].

Most of the industrial units are in Pimpri-Chinchwad and on the banks of Pavana River. With over 4,000 industrial units in the large, medium and small sectors dotting its landscape, the sprawling Pimpri-Chinchwad industrial belt is one of the largest of its kind in this part of the country and certainly boasts of some of the biggest names in the industry. Some of the names that it is home to include, Tata Engineering, Bajaj Auto, Hindustan Antibiotic, The Finolex Group of Industries and a clutch of Swedish companies that has made this twin city their home in the mid-sixties, including Sandvik Asia and Atlas Copco.

Fortunately, during last decade, World Bank and other organizations have done valuable research in different parts of India. One of the best studies we have ever found was about the Ganga River that has been done by Markandeya and Murty [3]. It was very useful for the researcher. We could not find any environmental economic study about Pune metropolitan region. Although many studies have been conducted about environmental pollution in the Pune Rivers, the economic aspect was not considered. Although, in other countries some valuable CVM studies have been done, for example Mourato [4] had computed the value of improvement of water quality for the biggest lake in Europe, lake Balaton. She utilized the Contingent Valuation Method (CVM). Georgiou and Batman [5] had combined the contingent ranking and contingent valuation study for valuation of river water quality. Soutukorva [6] computed the value of water quality by a random utility model of recreation in the Stockholm Archipelago. He examined how an improved water quality affects the demand for recreation in the Stockholm Archipelago. Soderquist [7] had used another method for a reduced entrophication in the Stockholm archipelago. The benefits of reduced eutrophication effects in Stockholm, Sweden, were estimated by the application of the contingent valuation method.

The paper is organized as follows: Section 2 describes the problem. The data collection work is summarized in section 3. Section 4 presents general empirical results, and detailed analysis of determinates of WTP and total user-benefit for improving water quality in Pavana River. Section 5 provides some concluding remarks and recommendations.

\section{The problem}

Nowadays, one of the important subjects in Environmental Economics is the pollution problem in industrial cities.

The Mula, Mutha and Pavana rivers, flowing through Pune City and the Pmpri-Chinchwad industrial area, are grossly polluted with untreated domestic sewage and partially or untreated industrial waste. The city is under continuous stress due to population growth, industrial growth and waste generation. The river water quality has deteriorated with respect to some of major water quality 
parameters, like Dissolved Oxygen (DO), Biological Oxygen Demand (BOD) and phosphates levels. In account of the Maharashtra Pollution Control Board (MPCB), all the pollution parameters are above permissible limits in Pune Rivers.

Water pollution is caused mainly by the discharge of untreated or inadequately treated sewage, industrial effluent and waste-water runoff from households. The absence or deficiency of sewage and refuse collection services causes water courses to become grossly polluted.

Polluted water can spread diseases amongst people who use it for washing, cooking or bathing. There is risk of contamination to ground water, water supplies from wells and agricultural users. Water pollution has its most immediate effect on human health through water borne diseases.

From an economical point of view, water pollution is a negative externality which decreases economic welfare or consumer utility. For example, people living near the Pune Rivers suffer from bad odours, mosquito and other problems. In fact, everyone who pollutes the rivers imposes some economic cost to other people. It is difficult to measure the effect of pollution on people's life and translating this effect to money, because for environmental goods, we do not have a market.

The rise in pollution in the Pune Rivers is due to growth in population and industries. Pune city has grown at moderate rates in the post-independence period from $2.2 \%$ to $3.5 \%$ per annum over the last four decades. In 1981, the population of Pune was 1,380,395 souls which has gone up to $1,560,000$ souls in 1999 and according to the 2001 census, the population of Pune City has reached the level of 2,640,000 souls. The city had a growth rate of about 60 per cent during the decade 1991-2001. The population of Pune City and PimpriChinchwad together was 4,000,000 in 2001. With such a high rate of growth in population, the discharge of domestic sewage into Mula, Mutha and Pavana rivers has gradually increased.

\section{Data collection work}

As is known, rivers are very important in our life. From a historical point of view, initial societies were established near to a water resource. So, many countries have a challenge because of water or the water share of common rivers. Fortunately, we have so many rivers in India. Pune is one of the richest in this aspect, because three rivers are flowing through the city. But it seems the quality of water should improve. For finding problems, first we visited the rivers, especially in the industrial area of Pimpri-Chinchwad. We observed that industrial effluent and domestic sewage contaminated the Pavana River. Many people are washing clothes and some people washing animals. Also, we saw slum areas near the river, they use the banks of the river for their toilet. After this visit we planned our research. We identified all the locations that have to be covered. We considered 1 kilometre $(\mathrm{km})$ from each bank of river in this stretch where the river passes through the city. We took decision to interview all kinds of people. Everybody, poor, rich, educated and uneducated participated in our 
study. Thus, we covered slum areas as well as other housing societies. Then we categorized respondents as follows:

1. Households;

2. Fishermen;

3. People bathing in the river;

4. Dhobi Ghat people (who use the river water for washing clothes); and

5. Farmers

We started from the Thergaon Bridge in Chinchwad and finished in Dapodi where Pavana joins the Mula River. For sampling we visited most of the societies along the river, choosing randomly. All societies and slum areas near the river participated in our sampling. We tried to interview the head of the family and if the head of the family was not available we interviewed the housewives or other knowledgeable members. Because I am an Iranian, one post-graduate person assisted me. The researcher himself conducted interviews with the help of the assistant, especially when the respondents could not speak English.

One of the most important steps in these types of studies (Contingent Valuation) is preparation of the questionnaire. We spent much time preparing it. After pre-testing of the first questionnaire, the final one that was used had the following features:

\subsection{Socio-economic details}

The first section of the questionnaire collected information on socio-economic variables to be used in the regression estimation of the valuation function. Apart from the name of the respondent and the address, information was collected on age, sex, occupation, education and family members.

Because people are sensitive about disclosing their income, we put the income question at the end of questionnaire. For finding the real economic situation we classified families into five categories (very poor, poor, middle class, upper middle class and rich). This was done because some people refused to disclose their income or told us a wrong amount of income. This part of the questionnaire was filled in by us with respect to our evaluation. For classification, we considered some parameters like the type of house, nature of furniture, respondent's job and our view. For example, Dhobi Ghat women are really poor, no doubt; while most of farmers are better placed economically. About the household - most of them were working for companies and belong to the middle class.

Moreover, we designed two questions about the kind of house in respect to whether it is rented or owned and the size or type of the house (hut/kachcha house, pucca house, small flat, big flat, small bungalow and big bungalow).

In the second part of questionnaire we designed some questions about environmental problems, the quality of water in Pavana, cause of pollution, NGO's and municipal policy about the river, and the end of this section carried questions designed to make the respondent think about the river pollution and his /her responsibility towards action to clean the river. 
We tried to prepare respondents for the last part of questionnaires by short, multiple-choice questions designed to deliver additional information in small doses, which are easier to assimilate.

\subsection{Value elicitation}

Value elicitation was the most crucial section of the questionnaire. First we described the Pavana Action Plan for improving river quality and then in order to tackle the part of problem, the respondents were given examples of private goods to illustrate the link between willingness to pay (W.T.P.) for benefits received (for example, we are willing to pay Rs ' $\mathrm{X}$ ' for a pen because we expect at least Rs ' $\mathrm{X}$ ' worth of benefits in return). Also we showed some photos that were taken from different parts of river.

In the pre-testing step, we introduced three payment vehicles. Because we wanted to elicit the true value of environmental quality, we gave people freedom to choose the payment vehicle. After they mentioned W.T.P we asked, "To whom you want to pay?" Most of people replied "to P.C.M.C" (PimpriChinchwad Municipal Corporation), but some people replied as 'Charitable Trust' and some replied as 'NGO. Thus, municipal taxes were chosen. For obtaining better results, we combined a payment card and open-ended format for W.T.P. question. We also utilized some photographs which showed pollution in the Pavana River.

I should mention here that we brought some descriptive questions in the middle part of the questionnaire about the government, P.C.M.C and NGO's policy and at the end of questionnaire we requested respondents' suggestions about the Pavana River. Moreover, we designed special questions for fishermen, farmers, Washing cloth people and bathers, and attached them to the main questionnaire.

In contingent valuation, we asked people as to how much they are willing to pay for utilizing a better quality of environmental goods. CVM is one of the most popular methods for environmental valuation. It was used in developing countries as well as developed countries. Also, we found some CVM studies in India that were done by the World Bank. When market data is not available this method can be used, although CVM should be used carefully.

As we said, the survey and data collection was carried out by personal interviews of local residents in the Pimpri-Chinchwad area. Respondents were interviewed at their residence and interviews were undertaken over the period from December 2004 to January 2005. Each interview lasted about 30-45 minutes. After socio-economic questions, we considered information related to people's visits and the use and perceptions of the Pavana river area.

One of the positive points in our work was that people living in PimpriChinchwad were very familiar with the problems and we had good response. Thus, the number of "No Response" answers was very few. As we expected, the quality of river water has been evaluated as "Dirty" by $76 \%$ of respondents, only about 18 percent thought it is bathable and less than one percent told us it is drinkable, Dumping of factory water, sewage from citizens, seepage from garbage dumps, idol immersion and washing clothes or animals were different 
causes of the Pavana river pollution. During our various visits we saw all the pollution sources around the Pavana River. Fortunately, cleaning the river water was very important for about 94 percent of respondents.

One of the most important aims of our research is finding relation between industrial growth and pollution. More than 89 percent of respondents thought industrial growth in the PCMC area during last two decades has increased river pollution. Regarding responsibility for improvement in water quality, 77 percent said PCMC, 58 percent said industrial sector and about 50 percent said people are responsible.

As mentioned, 305 people were interviewed. We visited all societies and slum areas near the banks of the Pavana River. Respondents were chosen randomly.

Households, fishermen, farmers, washing cloths women and people who bathe in the river were interviewed by us. Out of the sample, 63 percent were male, 37 per cent female. The average age of respondents was 37.65 and the mean period of living in the Pimpri-Chinchwad area was calculated at 15.14 years. The main questionnaire gathered information about age, gender, education, size of family, annual family income, people's ideas about social problems, environmental problems, municipal and government policy about river, river water quality, causes of river pollution and ways for preventing water pollution.

Researchers received very good responses from people; respondents were really keen to help us. At the end of questionnaire, we explained the Pavana Action Plan to the respondents and in account of we don't have a market for public goods like the river. We asked people whether they are willing to pay (W.T.P) some money and get a clean river (up to swimming level). In fact, the contingent valuation method was used for calculating preferences of the people.

\section{Major findings}

As mentioned in the previous section, 305 people were interviewed. The average age of the sample was 37.65 years old and the average size of the family obtained 4.67.

Table 1: $\quad$ Mean and standard deviation of different variables.

\begin{tabular}{|l|l|l|}
\hline Different variables & Mean & Std. Deviation \\
\hline Age & 37.65 & 12.90 \\
\hline Size of the family & 4.67 & 3.06 \\
\hline Period of living in Pimpri Chinchwad & 15.14 & 14.66 \\
\hline Annual income of the family & 126749.74 & 139996.14 \\
\hline Monthly income of the Respondent & 16957.41 & 57215.50 \\
\hline Willingness to pay (Total sample) & 17.63 & 81.25 \\
\hline Positive WTP & 22.40 & 91.04 \\
\hline
\end{tabular}


The mean average of WTP for illiterate respondent was Rs. 5.36 while for educated people (university/diploma degree) it was Rs. 22.31, table 2 shows the details. During sampling we met some uneducated people that were very cooperative. As is mentioned in the previous section the total average WTP is 17.55 .

Table 2: $\quad$ WTP in base of educational levels.

\begin{tabular}{|l|l|l|}
\hline Educational level & Mean & SD \\
\hline Illiterate & 5.36 & 7.09 \\
\hline Just Literate & 25.50 & 34.65 \\
\hline Primary & 5.00 & 5.00 \\
\hline Secondary & 17.50 & 98.22 \\
\hline Higher Secondary & 10.02 & 15.34 \\
\hline Diploma / Degree & 22.31 & 87.72 \\
\hline
\end{tabular}

The mean average and S.D. of WTP for different economic classification is presented in Table 3. As we expected, the mean WTP for the very poor is below Rupee 1, while for rich people it is Rs. 370. These results are completely consistent with economic theory and are a good witness of the validity of the research.

Table 3: $\quad$ WTP in base of economic classification.

\begin{tabular}{|l|l|l|}
\hline Economic classification of family & Mean & SD \\
\hline Very Poor & 0.71 & 2.17 \\
\hline Poor & 4.68 & 4.89 \\
\hline Middle class & 12.75 & 14.36 \\
\hline Upper middle class & 43.59 & 169.76 \\
\hline Rich & 370.00 & 547.45 \\
\hline
\end{tabular}

As stated earlier, we did not consider non-user benefits in the research, because non-user is plausible for important case like the Ganga River. Ganga is important for all Indian people. Moreover, there could be some perceived benefits from knowing that a river of major religious significance is now cleaner. Every year many people visit the Ganga, but in the case of Pavana, the situation is different. Thus, we calculated user benefits for Pavana.

For this purpose we interviewed households, fishermen, farmers, Dhobi Ghat and bath taking people. We considered a distance of up to 1 kilometre from each bank of the river. As mentioned, the mean average of WTP for all users is Rs. 17.73 per family per month.

Taking account of the latest data, the population of Pimpri-Chinchwad is 10, 06,417 in the 170 sq. $\mathrm{km}$. area. Thus, density can be estimated as follows: 
Density per sq. $\mathrm{Km}=$ Total population/Sampling area $=\frac{p}{S A}=\frac{1006417}{23}=5920$

The length of the Pavana is $11.5 \mathrm{~km}$ inside the city. So the total sampling area is $23 \mathrm{~km}^{2}$ (11.5). (2)=23. Total user population can be estimated easily. (Sampling area) multiple (number of family) (23). $(5920)=1,36,160$ total user population

As per of Census 2001, household size is 4.9; therefore total families in our case can be calculated as below:

$$
\text { Number of family }=\frac{136160}{4.9}=27,787.7 \text { households }
$$

If we multiply this to Rs. 17.73 aggregate monthly benefits will emerge. Then the yearly amount also will be. $(17.73)(27,787.7)=4,92,676$. Total WTP per month 4, 92,676 (12) =59, 12,122 is total user benefit per year. As can be seen from the above, the total user benefit per year is about Rs.59 lakhs $(5,900,000$ Rupees and 46Rupees=1Dollar). It is approximately equal 128,261 US Dollar, per year.

\subsection{WTP Bid function}

Analysis of the bid function underlying the WTP responses was undertaken, with a range of explanatory variables being investigated. Linear and long functional forms were tested. The former seemed to perform better in terms of the statistical significance of regression coefficient; hence, we just report the linear functional form case here since this provides for ease in interpretation, the bid function can be written as follows:

$$
\begin{gathered}
W T P=f\left(X_{1}, X_{2}, \ldots \ldots \ldots, X_{K}\right) \text { that } \frac{d W T P}{d X 1} \geq 0 \\
W T P=a_{0}+a_{1} X_{1}+a_{2} X_{2}+\ldots \ldots \ldots .+a_{K} X_{K}
\end{gathered}
$$

where the $X_{1}+X_{2}$--------- $X_{k}$ are the values taken by the $K$ factors that the analyst believes may influence the WTP change experienced by the respondents. The $K$ coefficients $a_{0} a_{1}$------------ $a_{K}$ measure the impact of each of the factors on the change in WTP

Thus, WTP is a dependent variable. Explanatory variables are as follows:

$\mathrm{X}_{1}=$ per capita annual income of the family

$\mathrm{X}_{2}=$ period of living in Pimpri - Chinchwad

$\mathrm{X}_{3}=$ Size of the family

$\mathrm{X}_{4}=$ importance of cleaning river water

(Dummy: 1 if very important; zero otherwise)

$\mathrm{X}_{5}=$ number of visitors to Pavana river side.

(Dummy: 1 if visit daily; zero otherwise) 
Table 4 reports the estimated coefficients for the model specification found to have the 'best' fit of the self explanatory variables with the most statistically significant.

Table 4: $\quad$ Regression results.

Dependent variable: WTP

\begin{tabular}{|l|l|l|l|}
\hline Explanatory Variable & Coefficient & $T$ & Significance \\
\hline Intercept & -33.917 & -1.737 & .083 \\
\hline$X_{1}$ & $9.258 \mathrm{E}-04$ & 7.438 & 0.00 \\
\hline$X_{2}$ & 0.351 & 1.167 & 0.244 \\
\hline$X_{3}$ & 0.491 & 0.337 & 0.736 \\
\hline$X_{4}$ & 6.549 & 0.340 & 0.734 \\
\hline$X_{5}$ & 8.48 & 0.698 & 0.486 \\
\hline
\end{tabular}

Number of observation $=304$

$\mathrm{F} \quad=11.4545$

$\mathrm{R}^{2}=0.161 \quad$ Adj $\mathrm{R}^{2}=0.147$

Thus $\frac{d W T P}{X 1} \cong 9.258 E-4 \geq 0, \quad$ it means the income has a positive relation with WTP. Whilst the overall model is found to be statistically significant $(\mathrm{F}=11.4)$, its explanatory power is low, with around $16 \%$ of the variation in WTP being explained by the explanatory variables. Many factors need to be borne in mind here. Firstly, levels of explanatory power are notoriously low for such contingent valuation method values. Usually if $\mathrm{R}^{2}$ is bigger than 10 percent the model is acceptable, but an important variable in this type of CVM study is 'Income' Fortunately in our model, income has a positive relationship with WTP and is statistically significant. It proves the validity and reliability of research.

\section{Conclusions and recommendations}

Results of there study are briefly presented below:

1) On the basis of our survey, it was found that the river pollution issue is very important for most of people (more than 87 percent respondents in our study)

2) About 76 percent of respondents evaluated the Pavana River as a "Dirty River".

3) At the same time, it was observed that some poor people have positive WTP while some rich people were not ready to pay any money for improving water quality in Pavana. Mean of WTP for rich people was Rs. 370 while for poor Rs. 4.68 and for very poor it was Rs. 0. 71. For whole sample, mean of WTP was Rs. 17.55 per family, per month.

4) As expected WTP and education have strong relationship. For example the mean of WTP for illiterate people was Rs. 5.36 while for educated people (Diploma/ University Degree) was Rs. 22.31. It can also prove validity of present study. 
5) As we expected more than 89 percent believed that industrial growth in PMR has increased river pollution.

6) We presented some suggestions for cleaning the River most of people agree with these suggestions.

7) We requested people whether they want to participate in the 'Pavana Action Plan' for improving water quality. More than 78 percent replied positively. It proves that people really like the Pavana River.

8) Among the people who directly use the Pavana River, farmers were more co-operative for cleaning the river.

9) Average willingness to pay (WTP) for the whole sample is Rs. 17.55 per month per family. If we delete protest bid and zero WTP, mean of WTP will increase to Rs. 22.40 per family per month.

10) When researcher visited different spots of the River and were interviewing people, so many of respondents complained about industrial pollution. Especially fishermen and farmers who were affected by water pollution.

11) More than 75 percent of respondents expressed that the factors of the cause of pollution in the River are sewage from citizens, dumping of factory wastage, washing clothes and idol immersion.

11) Regression WTP bid function was significant for overall model $(\mathrm{F}=11.4)$. Explanatory power was low, but it is more than in other similar cases.

12) Coefficient of income in the regression model was positive and statistically significant. This is consistent with economic theory.

13) Aggregate WTP for all users of Pavana was estimated at about Rs. 59 Lakhs per year. (One lakh=Rs100,000).

For improving river quality much work should be done. Some of the recommendations are as follows:

1) Public awareness especially among slum-dwellers should be done by PCMC and NGOs. For example, erecting some boards with motto "Keep our River Clean',

2) MPCB and PCMC should monitor industrial effluents and the permits or No Objection certificates production should not be issued for industrial units polluting the river water.

3) Most of the farmers are willing to pay money as per government's rules. They will co-operate with PCMC if water quality of Pavana River is improved.

4) Some place with small treatment plant and pipe water should be made available to dhobis (washing cloths). All of them are ready to use such place.

5) At least one place for holy bath should be constructed. It should be done by means of a small diversion from the river, near Morya Temple. Diverted water stream should be kept open for bathing and the outlet of this diversion stream should be to a small treatment plant.

6) Consider punishment to everybody who pollutes river.

7) At least one ETP (effluent treatment plant) for small industrial units should be constructed by PCMC and the government. 


\section{References}

[1] Nagarkar, S., A Survey of the Water Quality of Mula, Mutha and Pavana, University of Pune: Pune, p.3, 1997.

[2] District Census Hand Book, Maharashtra, India, 1981, 1991, 2001.

[3] Markandeya, A. and M. N. Murty., A Cost-Benefit Analysis of the Gaga Action Plan: Cleaning-up the Ganges, Oxford University Press: New Delhi, pp.116-137, 2000.

[4] Mourato, S. 'Estimating the value of water quality improvement in Lake Balatona contingent valuation study', Report to DEXII, European Commission: Brussls, pp.22-23, 1997.

[5] Georgiou, S. and I. Bateman 'Contingent Ranking and Valuation of River Water Quality Improvement', CSERGE working Paper: Birmingham, pp. 12-20, 2000.

[6] Soutukorva, A. The value of improved water quality: A random utility model of recreation in the Stockholm Archipelago, Beijer: Sweden, 2001.

[7] Soderquist, T., The regional willingness to pay for a reduced eutrophication in the Stockholm archipelago, Beijer: Sweden, pp. 6-17, 2000. 